\title{
Robert Alexy and the Dual Nature of Law
}

\section{TORBEN SPAAK*}

Abstract. Robert Alexy's claim that law of necessity has a dual nature raises many interesting philosophical questions. In this article, I consider some of these questions, such as what the meaning of the correctness thesis is, whether Alexy's discourse theory supports this thesis, and whether the thesis is defensible; whether Alexy's argument from anarchy and civil war supports the claim that law of necessity has a real dimension; and what the implications are of the use of moral arguments, such as the argument from injustice, for the status of Alexy's inquiry.

\section{Introduction}

Robert Alexy maintains that law has a dual nature, in the sense that it necessarily has both a real and an ideal dimension, and that this feature is "the single most essential feature of law" (Alexy 2010, 180). He explains that the elements of authoritative issuance and social efficacy constitute the real dimension of law, whereas the claim to moral correctness makes up the ideal dimension. And, he points out, the dualnature thesis implies nonpositivism: "If one claims that social facts alone can determine what is and what is not required by law, that amounts to the endorsement of a positivistic concept of law. Once moral correctness is added as a necessary third element, the picture changes fundamentally. A non-positivistic concept of law emerges" (ibid., 167).

The dual-nature thesis raises many interesting philosophical questions, but I shall be content to consider just a few of them in this article. I shall consider (i) the meaning and defensibility of the correctness thesis, which has it that law of necessity raises a claim to moral correctness; (ii) the question of whether Alexy's discourse theoryaccording to which some legal claims, say, " $p$ is obligatory," are neither discursively

\footnotetext{
* Professor of jurisprudence, Department of Law, Stockholm University. I would like to thank the participants in the advanced seminar in practical philosophy, Uppsala University, especially Victor Moberger, for helpful comments on the article. I would also like to thank Christoph Bezemek, Åke Frändberg, and Karl Pettersson for helpful comments on various versions of the article, and Robert Alexy and the participants in the workshop Law in Quest of Its Promise: Discussing Professor Robert Alexy's Legal Theory at the Tallinn University School of Governance, Law, and Society for helpful comments on my presentation of the main ideas in this article. In addition, I would like to thank an anonymous reviewer for identifying difficulties in the text and for suggesting improvements. Last but not least, I would like to thank Robert Carroll for checking my English. As always, the author alone is responsible for any remaining mistakes and imperfections.
} 
necessary, nor discursively impossible, but are instead discursively possible, or, as I would say, discursively contingent-really supports the correctness thesis and, more generally, the claims of normative necessity that are involved in the analysis of the concept of law put forward by Alexy; (iii) the validity of the argument from anarchy and civil war, which Alexy adduces in support of his claim that law of necessity has a real dimension; and (iv) the implications for the status of Alexy's inquiry into the use of moral arguments-specifically, the argument from injustice-in this inquiry.

I am going to argue (A) that Alexy's correctness thesis is defensible, and that Joseph Raz's well-known objection-that the correctness thesis is merely a special case of a more general, conceptual thesis about intentional actions-does not undermine Alexy's inquiry into the nature of law; (B) that Alexy's discourse theory can indeed support the correctness thesis and the claims of normative necessity that are involved in the analysis of the concept of law put forward by Alexy; ${ }^{1}(\mathrm{C})$ that the argument from anarchy and civil war fails to establish the desired conclusion, that law of necessity has a real dimension; and (D) that Alexy's use of moral arguments in the analysis is incompatible not only with the view that Alexy is analyzing the concept of law, but also with the view that he is explicating (or rationally reconstructing) said concept.

I shall begin with a brief consideration of Alexy's thoughts on the debate about the concept of law and of the conceptual framework within which Alexy considers this debate (Sections 2-3). I then proceed to consider the correctness thesis and the correctness argument (Section 4) and Raz's above-mentioned objection to the correctness thesis (Section 5). Next, I consider, first, the above-mentioned problem of discursive possibility (Section 6), and then the claim that law of necessity has a real dimension and, in particular, Alexy's argument from anarchy and civil war in support of this claim (Section 7). The article concludes with a consideration of whether Alexy's inquiry into the nature of law is best seen not as an analysis of the concept of law, but as an explication of this concept, and of the permissibility of moral arguments in this inquiry (Section 8).

\section{The Debate about the Concept of Law}

The inquiry into the nature of law is usually (see, e.g., Hart 1961; Raz 2009), but not always (see, e.g., Moore 2000), conceived as an analysis of the concept of law. This is also Alexy's view. The task of the legal philosopher, Alexy explains, is to analyze the concept of law; and if the analysis is successful, the analyst has thereby clarified the nature of law. The relevance of conceptual analysis to the question of law's nature, he explains, is due to the fact that concepts necessarily have not only a conventional, but also an ideal dimension:

As products of a culture, concepts are socially established rules that concern the meaning of words. To this extent, concepts have a conventional character. They are conventional rules of meaning. But concepts [...] are conventions of a special kind. They claim, as Kant puts it, to be "adequate to the object" [...]. In this way, they are intrinsically related to the correctness or truth

1 The term discursive possibility is not ideal, because in any system of modal logic "necessary $A^{\prime \prime}$ entails "possible $A^{\prime \prime}(\square \mathrm{A} \rightarrow \diamond \mathrm{A})$ but contradicts "possible $-\mathrm{A}(\nabla-\mathrm{A})$." The problem, then, is that, on Alexy's analysis, contrary to what the reader is likely to assume, discursive necessity does not entail discursive possibility but contradicts it. 
of the propositions constructed by means of them. This claim to adequacy necessarily connects the concept of a thing with its nature. With concepts [...] one strives to grasp the nature of the things to which they refer as perfectly, as correctly, as possible. This is the nonconventional or ideal dimension of concepts. To the degree to which those who use a concept are successful in fulfilling the claim to adequacy necessarily raised by the use of that concept, to that degree the concept corresponds to the nature of its object. And it has universal validity to the degree it corresponds to its object. (Alexy 2008b, 291-2; see also Alexy 2017, 320-1)

The question Alexy is concerned with in The Argument from Injustice (Alexy 2002) is which concept of law is correct or adequate. He maintains that the core of the debate about the concept of law concerns the relation between law and morality: Whereas legal positivists espouse the separation thesis, which has it that the concept of law is to be defined so that no moral element is included, nonpositivists assert the connection thesis, which has it that the concept of law is to be defined so that moral elements are included (ibid., 3-4). I myself would say-and I believe this is the received view (see, e.g., Coleman 2001, 104; Hart 1958; Kelsen 1992, 56; Kramer 1999, 1-17)—that the separation thesis has it that there is no necessary connection between (the content of) law and morality, and I believe Alexy would accept this formulation, too. As I see it, the separation thesis thus conceived can very naturally be conceived as a thesis about the content of (first-order) legal statements, namely, a thesis according to which such legal statements do not entail (first-order) moral statements (on this, see Hart 1982, 159-61, 266-7); but it can also, and this is Alexy's view, be conceived as a thesis about legal character (or legal validity), according to which even (grossly) immoral norms can be part of law. If, then, legal positivists are in the business of analyzing the concept of law, as most of them seem to be, they must take the separation thesis to be part of the concept of law, to be conceptually necessary: $\square^{\mathrm{C}}-\square^{\mathrm{C}} \mathrm{A}$ (here $\square^{\mathrm{c}}$ stands for "is conceptually necessary" and $A$ stands for "morality and the content of law are connected"); and this means that, unlike those who reject the separation thesis, they cannot coherently maintain that certain norms lack legal character (or legal validity) on account of their (gross) immorality.

Alexy does not clearly distinguish between the separation thesis, conceived as a thesis about legal statements, and the separation thesis, conceived as a thesis about legal character, but it is clear from his discussion that he is primarily concerned to examine the truth of the latter thesis. The reason why Alexy focuses on the separation thesis is, of course, that he believes that this thesis is what legal positivists and nonpositivists disagree about. For, he points out (Alexy 2002, 4), no serious nonpositivist excludes from the concept of law the elements (strictly speaking, the concepts) of authoritative issuance and of social efficacy. My own view (Spaak 2003, 473), however, is that it is the social thesis which constitutes the backbone of legal positivism (see also Coleman 2001, 152; Raz 2008, 20), and that there are serious nonpositivist legal philosophers who do not accept the social thesis, at least not fully.2 To be sure,

${ }^{2}$ A case in point is Ronald Dworkin. His central idea is that a person who would construct the soundest theory of law should start out from the settled law, as he calls it, and produce a moral justification of the law thus conceived. This suggests that the social thesis is relevant at what Dworkin calls the preinterpretive stage. It is not, however, relevant at what he calls the interpretive stage. For it is clear that the soundest theory might yield a result that goes beyond the usual sources of law (legislation, precedent, custom), as they are understood and practiced in the relevant legal order. On this, see Dworkin 1986, 65-8. I discuss Dworkin's theory in Spaak 2007, $107-31$. 
the social thesis implies the separation thesis, provided that we assume Hume's law and take the separation thesis to be concerned with the content of law (Spaak 2003, 473 ), so that a rejection of the separation thesis implies a rejection of the social thesis (or Hume's law) and therefore a rejection of legal positivism. The affirmation of the separation thesis does not imply affirmation of the social thesis, however. But since (as we shall see) Alexy does reject the separation thesis within the perspective of a participant, though not within the perspective of an observer, and therefore rejects legal positivism, and since the adequacy of legal positivism is a question that underlies much of the discussion in this article, I shall accept his way of framing the debate between positivists and nonpositivists.

I just said that I think of the separation thesis as a thesis about the connection between (the content of) law and (true) morality. This is of interest in this context because, as we shall see (in Section 4), Alexy maintains that the legal order itself, as well as legal acts in general (acts in the law, court judgments, etc.), necessarily raise a claim to correctness, and that what follows from a failure to raise the claim to correctness, or to satisfy it once it has been raised, is in the overwhelming majority of cases not a lack of legal character, but only that the relevant legal entity or property is legally defective. So even if Alexy is right that law necessarily raises a claim to correctness, the impact on the separation thesis, conceived as a thesis about legal character (or legal validity), will be limited.

Let me conclude this section by noting that Alexy is careful to point out that the participants in recent debates about the concept of law agree, on the whole, that, in addition to the usual analytic arguments, they must take into account normative arguments, and that he takes this to mean that a conceptual connection between law and morality is itself neither conceptually impossible nor conceptually necessary (Alexy $2002,22)$. And he maintains, in keeping with this, that there are indeed necessary connections between law and morality, and not only within the perspective of a participant, but also within the perspective of an observer, namely, connections that are normatively necessary (ibid., 22-3). He is, however, as we shall see (in Section 3), quite clear that conceptual necessity and normative necessity are two very different notions.

\section{Alexy's Conceptual Framework}

Alexy (ibid., 23-35) is careful to point out that his discussion of the existence or nonexistence of a conceptual connection between law and morality proceeds within a conceptual framework that consists of a concept of law (i) that embraces a concept of validity, (ii) that views legal systems as systems of procedures, (iii) that adopts the perspective of a participant, and (iv) that operates with a distinction between qualifying and classifying connections between the moral and the legal quality of what purports to be a legal act, and that his conclusions have to be seen in light of these distinctions.

First, if we adopt a concept of law that does embrace a concept of validity, we can distinguish accordingly between valid and invalid legal norms, acts in the law, court decisions, etc.-if instead we adopt a concept of law that does not embrace a concept of validity, we cannot speak of invalid legal norms, etc. Alexy believes, however, that one may say with good sense that $N$ is a legal norm, even though $N$ is legally invalid, 
or that a contemplated ideal legal system will never be valid law, or, conversely, that the law (not the valid law) requires one to do X (ibid., 44-5).

Secondly, on Alexy's analysis, a legal system conceived as a system of procedures is a system of actions guided by, and in various ways dependent on, norms, whereas a legal system conceived as a system of norms is simply that and nothing more, that is, it includes no courts, no authorities, no legislature. Alexy adds that to view a legal system as a system of procedures is to refer to its internal side, and to view a legal system as a system of norms is to refer to its external side (ibid., 24-5).

Thirdly, a person who adopts the perspective of a participant is a person who is concerned with the rightness or goodness of the legal norms, and with their correct interpretation and application, whereas a person who adopts the perspective of an observer is a person who is not concerned with such questions, but only with the question of how courts and other law-applying organs do decide, or will decide, cases (ibid., 25). I suspect, however, that on this analysis, one cannot conceive of law as a system of procedures without also adopting the perspective of a participant, and vice versa. For I suspect that a reference to the internal side of law amounts to, or is very similar to, a reference to the participant perspective.

Fourthly, Alexy makes a distinction between classifying and qualifying connections between the moral and the legal quality of what purports to be a legal act (such as an act in the law or a piece of legislation). If a moral shortcoming leads to a loss of legal character, we are dealing with a classifying connection; if it leads only to a legal fault, we are dealing with a qualifying connection. And, he points out, the idea of a qualifying connection depends on the assumption that law has an ideal dimension (ibid., 26). That is to say, the reason why a moral shortcoming will amount to a legal fault is that the ideal dimension of law is a moral dimension and that a moral shortcoming will mar the ideal dimension.

As I understand it, the distinction between a legal norm, an act in the law, etc., that lacks legal character and one that is legally defective tracks the two versions of the so-called Radbruch formula, that is, the disavowal formula and the intolerability formula (on the Radbruch formula, see Alexy 1999, 16; Radbruch 2006, 7). For example, the thesis (which will be considered below in Section 4) that a (purported) legal system that does not raise a claim to correctness is not a legal system at all, is in keeping with the disavowal formula, according to which something that purports to be law, but does not even aim at justice, lacks legal character; and the thesis (which will also be considered in Section 4) that a legal system that does raise a claim to correctness but fails to satisfy it, is in keeping with the intolerability formula, according to which a legal system that conflicts with justice in an intolerable manner must, as flawed or lawless law, give way to justice.

Alexy adds a fifth distinction to the ones already considered, namely, the distinction between conceptual and normative necessity (Alexy 2002, 26). As Alexy sees it, to say that Smith is under a duty or an obligation to perform an action, $X$, is to say that $X$ is normatively necessary (for Smith). Alexy, however, is careful to point out that normative necessity is something very different from conceptual necessity, and that it is a type of necessity only in a wide sense of the word:

Normative necessity is strictly to be distinguished from conceptual necessity. That something is normatively necessary means nothing other than that it is commanded. One can, without contradicting oneself, challenge the validity of a command but not the existence of a conceptual 
necessity. It is clear that only in a broader sense, then, is normative necessity a necessity. (Ibid., 21, n. 40)

As we shall see (in Sections 7 and 8), the distinction between conceptual and normative necessity is highly relevant to the assessment of Alexy's argument from anarchy and civil war and to the question of the methodological status of Alexy's inquiry into the nature of law.

Having introduced the above-mentioned distinctions, Alexy explains that he is going to focus on the distinction between the perspective of a participant and the perspective of an observer. The question he intends to consider is whether the separation thesis, conceived as a thesis about legal character, or the connection thesis, is correct, and if so within which perspective (ibid., 51). Accordingly, he divides the analysis into two parts: one in which he adopts the observer perspective, and another in which he adopts the perspective of a participant. His position is that the separation thesis is correct, if we adopt the perspective of an observer (ibid., 27-35), and that it is incorrect (and the connection thesis is correct), if we adopt the perspective of a participant (ibid., 35-81). As a result, the truth or defensibility of Alexy's critique of legal positivism depends on which perspective is adopted. In what follows, I shall be focusing on Alexy's line of argument within the perspective of the participant.

\section{The Correctness Thesis and the Correctness Argument}

Alexy maintains that when seen from the perspective of a participant, the separation thesis is inadequate. But to see that this is so, he explains, we need to consider three distinct arguments, namely, the argument from correctness, the argument from injustice, and the argument from principles (Alexy 2002, 35-9). He reasons, more specifically, (i) that the argument from correctness establishes a conceptual connection between law and morality (ibid., 35-9); (ii) that the argument from injustice rebuts one possible objection to the argument from correctness, namely, that a failure to satisfy the claim to correctness will only result in a legally defective legal norm, court judgment, or legal system, not in a norm or judgment or norm system that lacks legal character (ibid., 40-68); and (iii) that the argument from principles rebuts another possible objection to the argument from correctness, namely, that the content of the claim to correctness lacks moral implications and that the claim to correctness is therefore unable to establish a conceptual connection between law and morality (ibid., 69-81). ${ }^{3}$ In what follows, I shall, however, only consider the correctness thesis and the correctness argument.

3 The argument from principles starts out from a distinction between rules and principles and says that the judge is bound also in the open area of the positive law (ibid., 68-70). The argument aims to lead, by way of three subtheses, to a necessary connection between law and morality. The subtheses are the incorporation thesis, according to which, necessarily, any minimally developed legal systems includes principles (ibid., 71-4); the (weak) morality thesis, according to which at least some of the principles the judge must invoke to satisfy the claim to correctness are part of some morality (ibid., 74-6); and the correctness thesis, which leads, together with the incorporation thesis and the morality thesis, to a necessary, if qualifying, connection between law and the idea of a correct morality (ibid., 76-81). Alexy points out that the connection thus established between law and the idea of correct morality is significant, because it can function as a so-called regulative ideal (ibid., 80-1). 
We see that the argument from correctness constitutes the foundation of Alexy's critique of legal positivism and that the function of the other two arguments-the argument from injustice and the argument from principles-is to supplement the argument from correctness. Moreover, Alexy's discussion makes it clear that whereas the argument from correctness and the argument from principles are conceptual arguments, the argument from injustice is a normative (or an evaluative) argument. This means that Alexy's critique of legal positivism depends partly, but unavoidably, on a normative (or an evaluative) argument. And, as we have seen, Alexy maintains that this implies that the (alleged) conceptual connection between law and morality, which he takes to be at the center of the positivism/nonpositivism debate, is itself neither conceptually impossible nor conceptually necessary, though it may be normatively necessary. Let us now consider the correctness thesis and the correctness argument.

Observing that only persons can make claims, Alexy $(1998,206)$ explains that the claim to correctness is raised by those persons who "act for and in law by creating, interpreting, using, and enforcing it." To clarify the sense in which the spokesmen of the law raise a claim to correctness, he introduces a distinction between a subjective and an objective raising of a claim and explains that he has in mind the latter alternative (ibid., 206): Whereas a person raises a claim subjectively if he wants to raise it, he raises a claim objectively if it is necessarily connected to his role as a participant in the legal system. The idea, then, is that the sense in which law necessarily raises a claim to correctness is that legislatures, judges, and others who participate in the legal system necessarily raise a claim to correctness in performing their specific legal task-if they didn't raise a claim to correctness, they would not be acting as participants in the legal system.

Invoking the distinction between classifying and qualifying connections, Alexy describes the consequences of a failure to raise a claim to correctness, or to satisfy it if it has been raised, as follows:

A system of norms that neither explicitly nor implicitly makes this claim is not a legal system. In this respect, the claim to correctness has a classifying significance. Legal systems that do indeed make this claim but fail to satisfy it are legally defective legal systems. In this respect, the claim to correctness has a qualifying significance. An exclusively qualifying significance is attached to the claim to correctness of individual legal norms and individual legal decisions. These are legally defective if they do not make the claim to correctness or if they fail to satisfy it. (Alexy 2002, 35-6)

As I have said (in Section 3), I believe that in making a distinction between an entity or a property that lacks legal character and one that is legally defective, Alexy is following the two versions of the Radbruch formula, the disavowal formula and the intolerability formula. But, one wonders, why does he treat legal systems, on the one hand, and legal norms and judgments, on the other, differently? Surely, it could be the case that an individual norm or a court judgment did not even aim at justice, and in such a case one might argue, in keeping with the disavowal formula, that it lacked legal character. One may also wonder whether it makes sense to say that a legal system raises a claim to correctness in a way that does not include each and every legal act, or at least most such acts, raising a claim to correctness. For example, could there be a situation in which a legal system raises a claim to correctness, even though none or very few legal acts in that system raise such a claim? If so, in what sense does the 
legal system raise a claim to correctness? If not, what does the idea of a legal system raising a claim to correctness add to the idea of a number of legal acts raising such a claim? Finally, one may well wonder if Alexy is not simply contradicting himself when he maintains both (i) that legal acts necessarily raise a claim to correctness and (ii) that legal acts that do not raise a claim to correctness are legally defective. If it is conceptually necessary that a legal act, $X$, raise a claim to correctness, how could $X$ not raise a claim to correctness while remaining an $X$ ?

We see here that legal positivists do not have to be terribly worried by Alexy's critique, because even if Alexy is right, the separation thesis, conceived as a thesis about legal character, would fail to hold only if a purported legal system did not even raise a claim to correctness, and this would surely be unusual. If instead a legal system raised a claim to correctness without satisfying it, or if an individual legal act either did not raise a claim to correctness, or did raise it without satisfying it, the result would only be a legal fault, not the loss of legal character, and this means that the separation thesis thus conceived would still stand. However, we also see that if Alexy is right, the separation thesis conceived as a thesis about the content of legal statements will be undermined. For the import of the correctness thesis appears to be precisely that legal statements entail moral statements.

In any case, to justify the correctness thesis, Alexy considers a hypothetical constitutional article (CA) and a hypothetical court judgment (CJ) (ibid., 35-9). His strategy is to identify an absurdity in the very idea of a legal act-such as an act of legislation or a court judgment- that is not connected with a claim to correctness, and to argue that this absurdity can only be explained by reference to the occurrence of a performative contradiction, which (in a wide sense) is a conceptual defect. The constitutional article reads as follows:

(CA) $\mathrm{X}$ is a sovereign, federal, and unjust republic.

And the court judgment reads as follows:

(CJ) The accused is sentenced to life imprisonment, which is an incorrect interpretation of prevailing law.

Beginning with (CA), Alexy points out that the absurdity is not due to a technical, moral, or conventional fault, but to (what he calls) a performative contradiction. What he means is that the reason we find (CA) absurd is that the act of legislation necessarily involves the raising of a claim to correctness, and that this claim to correctness is contradicted by the content of (CA). To enact (CA), then, is to make a conceptual mistake (in a wide sense) (ibid., 37-8). Turning to (CJ), he applies the same type of reasoning. That is to say, he argues that the reason we find (CJ) absurd is that the act of rendering a judgment necessarily involves the raising of a claim to correctness, and that this claim to correctness is contradicted by the content of (CJ) (ibid., 39). Since this is so, we have in this case, too, a performative contradiction and thus a conceptual mistake (in a wide sense).

The question, however, is whether such an argument from performative contradictions is powerful enough to establish a conceptual truth, namely, that law raises a claim to correctness. I believe it is. Generally speaking, there are logical contradictions and pragmatic contradictions. However, a performative contradiction is neither 
a logical nor a pragmatic contradiction, but appears to be something in between. For whereas a logical contradiction is generated by a logical implication, a pragmatic contradiction is generated by a pragmatic implication, in the sense that it arises when a person who asserts $A$ typically implies $B$ where $B$ contradicts $A$ (see Foley 1999, 730). On Alexy's analysis, a performative contradiction is instead a contradiction that arises when an agent is misusing a concept that is involved in his claim. For example, to assert "the cat is on the mat, but I don't believe it" is to fail to appreciate that knowledge (I know the cat is on the mat) implies belief (I believe the cat is on the mat); and to assert " $X$ is a sovereign, federal, and unjust republic" is to fail to appreciate that the act of legislation implies a claim to (moral) correctness that contradicts the content of this statement.

As we have seen, Alexy maintains that the necessary existence of the claim to correctness is the best explanation of why we find (CA) and (CJ) absurd. In the process of justifying this inference, as we have also seen, he considers and rejects certain other possible explanations of the absurdity, namely, that (CA) and (CJ) are technically, conventionally, or morally faulty (Alexy 2002, 36-7). Thus conceived, the argument that is meant to establish the necessary existence of the claim to correctness has the structure of an inference to the best explanation (on this type of inference, see Harman 1965) and is a species of inductive inference.

\section{The Correctness Thesis and the Appropriateness Thesis}

Joseph Raz (2008) objects to Alexy's analysis that the correctness thesis is really a special case of a more general thesis about intentional action, according to which every intentional action commits its agent to its own appropriateness, ${ }^{4}$ and that Alexy cannot use the correctness thesis to clarify the nature of law, but must instead use his theory of law to clarify the correctness thesis. For example, if the claim to correctness has a moral content, as Alexy holds, then this is so, according to Raz, because it follows from the nature of law, not from the nature of intentional action, and this means that the correctness thesis, which is a purely formal thesis, will be of no help to one who wishes to inquire into the nature of law (ibid., 28). Here is Raz:

The thesis is formal in that it does not determine what standards apply. Obviously, since it is so general, applying to all purposeful conduct, it cannot do that. Different standards apply to different activities and pursuits. It is the nature of various activities, and the circumstances in which they are undertaken, which determines which standards apply to them. If the law is committed to standards of justice this follows from the nature of law, not from the nature of purposeful activity. It follows that nothing can be learnt from the correctness thesis about the nature of law. Rather, once we have established, in light of other arguments, what is the nature of law, and only then, will we be able to conclude which commitments the law makes, or what claims it makes. The correctness thesis, being a formal thesis, while true, offers no specific help in elucidating the nature of law. (Ibid., 28)

Raz's line of argument gives rise to two questions. First, is it a conceptual truth that one who performs an intentional action raises a claim to appropriateness in the sense

4 On Raz's analysis $(2008,26)$, such a commitment to appropriateness means that "if an agent acts intentionally and is proven to have acted inappropriately or unwisely, or in some other way to have acted as he should not have, he must, once convinced of his mistake, believe that he should not have acted as he did, on pain of irrationality." 
explained by Raz? Does it make sense to maintain that this thesis applies to all intentional actions, even more or less trivial ones, such as brushing one's teeth, or combing one's hair, or getting dressed? As for less trivial actions, is it a conceptual truth that Pablo Escobar or "El Chapo" Guzman raised claims to appropriateness when they were selling drugs, bribing policemen or politicians, or threatening or assassinating journalists, policemen, and politicians? I doubt it.

Secondly, even if Raz is right, that it is a conceptual truth that a person who performs an intentional action raises a claim to appropriateness, and that the correctness thesis is a special case of such a more general, conceptual thesis about the appropriateness of intentional actions, it does not follow that Alexy cannot use the correctness thesis to throw light on the nature of law. As we have seen, Alexy invokes two arguments (featuring the constitutional article and the court judgment, respectively) in support of the correctness thesis, and if these arguments are cogent, he has shown that (what he refers to as) the claim to correctness has a moral content; and this in turn means that he has shown us something about the nature of law, namely, that it has an ideal, or moral, dimension established by the necessary claim to correctness. Thus I am inclined to believe that we can view the correctness arguments adduced by Alexy together with his discussion of those arguments as an independent, small-scale inquiry into the nature of law (like the one Raz requests), the result of which is then reported by Alexy using the notion of a necessary claim to correctness.

It is interesting to note that Alexy raises a very different objection to Raz's critique of the correctness thesis. He maintains that there is an important difference between the claim to correctness and Raz's claim to appropriateness, namely, that whereas the former is or, perhaps, entails a further claim to be accepted by all, a claim to objectivity, which in turn points to the ideal dimension of law, the same cannot be said about the latter. Alexy does not explain what he takes objectivity to amount to in this context, but I take it he means something like truth or validity of legal statements independently of one's moral or legal perspective. He writes:

A bandit who claims that his action is self-enriching does not thereby claim that his action, for that reason, has to be accepted by everyone, even by his victims. This is altogether different in case of the claim to correctness. The claim to correctness is a claim that is addressed to all. In this respect, it is similar to a claim to truth. A claim that is addressed to all is, at the same time, a claim to objectivity. As such, both are, indeed, formal. But as a claim that refers to objectivity, the claim to correctness is by no means trivial. Objectivity is not only anything but trivial, it also belongs necessarily to the ideal dimension of law. Thus, the claim to correctness, notwithstanding its formal character, points to the ideal dimension of law. (Alexy 2010, 170; see also Alexy 2008a, 49)

I believe Alexy is mistaken here, however. I believe Raz's claim to appropriateness is precisely a claim addressed to all, and that it is in this sense a claim to objectivity, though we must make a distinction between appropriateness as a bandit action and the moral appropriateness of the bandit action. On Raz's analysis, while a bandit who performs a bandit action necessarily raises a claim to be performing an appropriate bandit action, he is by no means claiming that the victims of his action must accept the moral appropriateness of this action; and this means that Alexy overshoots the mark when he insists (in the quotation above) that "[a] bandit who claims that his action is self-enriching does not thereby claim that his action, for that reason, has to be accepted by everyone, even by his victims." This is true, but beside the point. The 
relevant claim, which is indeed a claim to objectivity, is the more limited claim that the action is, objectively speaking, appropriate as a bandit action, ${ }^{5}$ and this claim is addressed to all.

I conclude that even if Raz is right that the claim to correctness is only a special case of the claim to appropriateness, and that Alexy therefore cannot use the correctness thesis itself to throw light on the nature of law, but must instead inquire into the nature of law in order to throw light on the correctness thesis, Alexy has actually carried out a mini-inquiry into the nature of law by adducing and discussing the two correctness arguments and has used insights gained from this mini-inquiry to clarify the content of the claim to correctness. I also conclude that in any case, Alexy's objection to Raz's critique, discussed above, is not persuasive.

\section{Discourse Theory-a Difficulty}

The claim to correctness, as we have seen, has a significant moral content, and this means that it is a claim about moral correctness. But, one wonders, is there such a thing as moral correctness at all? Kelsen (1960, 65-71), for example, holds that morality is relative to groups of people, and that one reason to reject natural law theory is precisely that it is premised on the false assumption that there is such a thing as nonrelative moral correctness. Alexy $(2010,171-2)$ retorts that his discourse theory of practical reasoning-which has it that a practical or normative statement is correct if, and only if, it can be the result of a rational practical discourse-holds the answer to such worries about moral correctness:

Discourse theory is a procedural theory of practical rationality. [...] The conditions of discursive rationality can be made explicit by means of principles, rules, and forms of general practical discourse [...]. This system comprises rules that demand non-contradiction, clarity of language, reliability of empirical premises, and sincerity, as well as rules and forms that speak to the consequences, and to balancing, universalization, and the genesis of normative convictions. The procedural core consists of rules that guarantee freedom and equality in discourse by granting to everyone the right to participate in discourse and the right to question as well as to defend any and all assertions. (Ibid., 172)

Alexy candidly admits, however, that following the rules of discourse does not guarantee that there will always be a right answer to moral or, more generally, practical questions:

Along with discursive necessity and discursive impossibility, there exists [...] a broad range of what is merely discursively possible. A judgment is merely discursively possible when one person can justify this judgment without violating any rule or principle of discourse, while another person, at the same time, can do the same with respect to the contradictory of this very judgment. In such a case, incompatible judgments are backed by reasons. (Ibid., 172-3; footnote omitted, italics added; see also Alexy 1989, 206-8)

The idea, then, is that while the result of discourse will in some cases be that the claim under consideration, say, $\mathrm{Op}$, is discursively necessary ( $\left.\square^{*} \mathrm{Op}\right)$, in the sense that it can

${ }^{5}$ I am here assuming, for the sake of argument, that Raz is right that it is a conceptual truth that all intentional actions raise a claim to appropriateness, even though I said above that I doubt that this is so. I must admit, however, that I find it difficult to say what the content of a claim to the appropriateness of a bandit action might be. 
be the result of discourse in accordance with the rules of discourse, or discursively impossible $\left(-\diamond^{*} \mathrm{Op}\right)$, in the sense that it cannot be the result of such discourse, it will sometimes be discursively possible (or discursively contingent) ( $\diamond^{*} \mathrm{Op} \& \diamond^{*}-\mathrm{Op}$ ), in the sense that both it and its contradictory can be the result of discourse. As I understand it, this means that $O p$ is discursively necessary if, and only if, $O p$ can be the result of discourse according to the rules and -Op cannot be the result of such discourse (for if $-\mathrm{O} p$, too, could be the result of such discourse, we would have a case of discursive possibility), and that $O p$ is discursively impossible if, and only if, $O p$ cannot be the result of discourse. Note that one must not confuse the claim under consideration in discourse, $O p$, with the discourse claim that $O p$ is discursively necessary ( $\square^{*} \mathrm{Op}$ ), possible $\left(\nabla^{*} \mathrm{Op} \& \diamond^{*}-\mathrm{Op}\right)$, or impossible $\left(-\diamond^{*} \mathrm{Op}\right)$.

Alexy's position on discursive possibility strikes me as reasonable. For I believe it would be naïve to think that discourse according to the formal and general rules of discourse can in all cases yield the result that either $O p$ or its contradictory, $-O p$, is the case. One may, however, wonder if this rather modest metaethical theory really holds the answer to Kelsenian worries about moral correctness. For one might be tempted object that if $\mathrm{Op}$ and all other legal claims necessarily raise a claim to moral correctness, if discourse theory allows that both $O p$ and $-O p$ can be the result of discourse, and if such discursive possibility means, as I believe it means, that there is no moral correctness as regards $O p$, then the correctness thesis conceived as a general thesis about legal acts is premised on an assumption of moral correctness that is false because too strong, even by Alexy's own account.

I do not, however, think that this is a problem. Whereas natural law theory maintains that law is necessarily moral in the strong sense that Kelsen rejects, Alexy does not claim that law is necessarily moral, but only that law necessarily raises a claim to moral correctness, and this means that the correctness thesis is compatible even with error theory. For on an error-theoretical analysis, the claim to correctness would always be false. This would not, however, undermine Alexy's theory, because the theory does not assume that the claim to correctness is in every case satisfied. To the contrary, as we have seen (in Section 4), Alexy maintains that if a legal system, or an individual legal norm or decision, raises a claim to correctness but fails to satisfy it, the legal system, norm, or decision will be legally defective in the sense that its ideal dimension will be marred. Alexy does not, of course, espouse error theory, but he does defend discourse theory, according to which there is not only discursive necessity, but also discursive possibility (or contingency); and this means that he will have to accept that in some, perhaps quite a few, cases, the relevant legal entity or property will be legally defective. However, as we have just seen, Alexy does accept that this is so.

One might be tempted to defend Alexy by arguing that discourse theory could contemplate degrees of correctness and view some legal claims as more correct than others, on the grounds that they have been verified through better deliberation, and that one could therefore say that the correctness thesis makes sense even in cases of discursive possibility. ${ }^{6}$ I do not, however, think it would be illuminating to say that a legal claim would have a lower degree of correctness if it were discursively possible than if it were discursively necessary, or that it would have a lower degree of correctness in one case of discursive possibility than in another, or, for that matter, that in the

${ }^{6}$ I would like to thank an anonymous referee for suggesting this line of argument. 
case of discursive possibility two contradictory claims would have the same degree of correctness. For the very idea of degrees of correctness, like the idea of degrees of truth, is quite problematic and would need to be explicated with great care. In my view, as I have indicated above, the better view is to say that in cases of discursive possibility, there is no moral correctness at all.

I believe the findings in this section will be of interest not only as regards the correctness thesis, but also as regards the methodological status of Alexy's inquiry into the nature of law. For, as we have seen (in the quotation in Section 2), Alexy maintains that concepts claim to be "adequate to the object," that in this way they are "intrinsically related to the correctness or truth of the propositions constructed by means of them," and that with concepts "one strives to grasp the nature of the things to which they refer as perfectly, as correctly, as possible." If, then, Alexy's analysis of the concept of law involves moral arguments, such as the argument from injustice, Alexy must reasonably mean to say that those arguments are correct-if they were not correct, he could not reasonably be striving in his analysis to grasp the nature of law "as perfectly, as correctly, as possible." If, however, he intends discourse theory to establish the correctness of the moral arguments he adduces, and if he also admits that in some cases discourse theory will deliver the result that both the claim under consideration and its contradictory are justified, so that the claim in question is merely discursively possible, then he will have to accept that the analysis cannot in those cases grasp the nature of law as perfectly, as correctly, as possible. This is not a problem for Alexy, however. For it is clearly not Alexy's position that each and every moral claim adduced in an inquiry into the nature of law is morally correct.

\section{The Real Dimension of Law: Anarchy and Civil War}

The argument adduced by Alexy in support of the claim that, necessarily, law has a real dimension, in addition to the ideal dimension, which (we assume) has been established by the necessary claim to correctness, is that law needs a real dimension in order to avoid the costs of anarchy and civil war and achieve the advantages of social coordination and cooperation:

The insufficiency of the ideal dimension qua decision procedure necessitates as its complement the existence of the real, that is, the positive dimension of law. This necessity stems from the moral requirements of avoiding the costs of anarchy and civil war and achieving the advantages of social co-ordination and co-operation. (Alexy 2010, 173; see also Alexy 2018, 256) ${ }^{7}$

I believe this brief, rather sketchy argument can be spelled out as follows: Necessarily, law has a real dimension (1) because law necessarily raises a claim to correctness; (2) because it is normatively necessary (obligatory) that the claim to correctness be satisfied; (3) because avoiding civil war and anarchy and achieving social coordination and cooperation is necessary in order to satisfy the claim to correctness; and (4) because the existence of the real dimension is necessary to avoid anarchy and civil war,

7 This argument is further developed in Alexy $(2017,322-3)$. Here Alexy argues that the reason why the real dimension is a necessary complement to the ideal dimension is, crudely put, (i) that our practical knowledge is limited, (ii) that spontaneous compliance is not enough, and (iii) that organization presupposes law. It seems to me, however, that in listing (i)-(iii) Alexy is refining, rather than adding something new to, the argument from anarchy and civil war. 
etc. I believe the logical form of the argument can be spelled out in the following way ( $\square^{\mathrm{C}}$ stands for "is conceptually necessary"; $\square^{\text {nor }}$ stands for "is normatively necessary (is obligatory)"; $\square^{\text {nat }}$ stands for "is "naturally' necessary"; C stands for "law raises a claim to correctness"; S stands for "the claim to correctness is satisfied"; A stands for "there is anarchy and civil war, etc."; and R stands for "law has a real dimension":

\begin{tabular}{llll}
\hline$\left(1^{*}\right)$ & $\square^{\mathrm{c}} \mathrm{C}$ & premise & (the correctness thesis) \\
$\left(2^{*}\right)$ & $\square^{\text {nor }}(\mathrm{C} \rightarrow \mathrm{S})$ & premise & (Alexy 2002, 73) \\
$\left(3^{*}\right)$ & $\square^{\text {nat }}(\mathrm{A} \rightarrow-\mathrm{S})$ & premise & (the quotation above) \\
$\left(4^{*}\right)$ & $\square^{\text {nat }}(-\mathrm{R} \rightarrow \mathrm{A})$ & premise & (the quotation above) \\
$\left(5^{*}\right)$ & $\square^{\text {nor }}$ & 1,2 & (the means /end principle) \\
$\left(6^{*}\right)$ & $\square^{\text {nat }}(-\mathrm{R} \rightarrow-\mathrm{S})$ & 3,4 & (the syllogism principle) \\
$\left(7^{*}\right)$ & $\square^{\text {nat }}(\mathrm{S} \rightarrow \mathrm{R})$ & 6 & (contraposition) \\
$\left(8^{*}\right)$ & $\square^{\text {nor }} \mathrm{R}$ & 5,7 & (the means/end principle) \\
\hline
\end{tabular}

I am assuming here the outlines of a bimodal system of logic, that is, a system that includes both deontic and (alethic) modal operators, together with axioms for the respective type of operator and rules of inference that can handle the interaction between different types of operators. The argument thus conceived is problematic, however. First, the argument features two versions of the so-called means/end principle, ${ }^{8}$ namely, $\square \mathrm{A}, \mathrm{O}(\mathrm{A} \rightarrow \mathrm{B}) \vdash \mathrm{OB}$, which takes us from $\left(1^{*}\right)$ and $\left(2^{*}\right)$ to $\left(5^{*}\right)$, and $\mathrm{OA}$, $\square(\mathrm{A} \rightarrow \mathrm{B}) \vdash \mathrm{OB})$, which takes us from $\left(5^{*}\right)$ and $\left(7^{*}\right)$ to $\left(8^{*}\right)$. The second (latter) version is problematic, however, because it gives rise to the so-called Good Samaritan paradox (on this paradox, see Åqvist 1967), which is as follows. We assume that a Good Samaritan finds a wounded traveler on the road, and that he ought to help the traveler. We then see that it is necessary that if the Good Samaritan binds the traveler's wound (B), then there is a wounded traveler $(W): \square(B \rightarrow W)$; and we can conclude, in keeping with the means/end principle, that since the Good Samaritan ought to bind the traveler's wound (OB), the traveler ought to be wounded $(\mathrm{OW})$; and this does not seem right.

James Garson $(2007,46-8)$ proposes a way to escape the paradox, however, which I find appealing (but see Åqvist 1967, 369-70; Pettersson 2010, 50-3). He points out (i) that the premise that the Good Samaritan binds the traveler's wound (called $B$ above) can actually be divided into two subclaims, namely, that the traveler is wounded (W) and that the Good Samaritan binds the traveler's wound (B), thus (W\&B); (ii) that it is necessary that if $(W \& B)$, then $(W)$; and (iii) that $(O W)$ follows from $\square(W \& B \rightarrow W)$ $\& O(W \& B)$ according to the means/end principle. But, he observes, the premise $\mathrm{O}(\mathrm{W} \& \mathrm{~B})$ is actually false as it stands (since $O W$ is false), and we therefore need to reformulate it in such a way that the $O$ operator takes narrow scope, (W\&OB), instead of wide scope, $\mathrm{O}(\mathrm{W} \& \mathrm{~B})$. If we do, the means/end principle will no longer be applicable, since the "narrow scope" premise (W\&OB) has the wrong logical form. Hence, the offending conclusion, (OW), does not follow.

Secondly, the conclusion, $\left(8^{*}\right)$, is formulated in terms of normative necessity, even though an inquiry into the nature of law, as Alexy understands it, amounts to an analysis of the concept of law, so that conceptual necessity is needed. The reason why

8 The means/end principle is a theorem of most bimodal systems of logic. Rönnedal (2012, $20-1,49-54,217-40)$ formulates it as follows: "every necessary consequence of what ought to be ought to be." 
the conclusion is not-and cannot be-formulated in terms of conceptual necessity is that the premises are not all formulated in terms of conceptual necessity. For just as factual premises cannot entail a conclusion formulated in terms of any kind of necessity, ${ }^{9}$ so premises formulated in terms of natural necessity or normative necessity cannot entail a conclusion formulated in terms of conceptual necessity. If we again consider the premises, we see that $\left(1^{*}\right)$ is formulated in terms of conceptual necessity, that $\left(2^{*}\right)$ is formulated in terms of normative necessity, and that $\left(3^{*}\right)$ and $\left(4^{*}\right)$ are formulated in terms of what we might call "natural" necessity. As a result, $\left(5^{*}\right)$, which follows from $\left(1^{*}\right)$ and $\left(2^{*}\right)$, is formulated in terms of normative necessity; $\left(6^{*}\right)$, which follows from $\left(3^{*}\right)$ and $\left(4^{*}\right)$, and $\left(7^{*}\right)$, which follows from $\left(6^{*}\right)$, are formulated in terms of "natural" necessity; and $\left(8^{*}\right)$, the conclusion, which follows from $\left(5^{*}\right)$ and $\left(7^{*}\right)$, is formulated in terms of normative necessity.

Thirdly, the justification of $\left(2^{*}\right)$ is problematic. Although Alexy $(2002,73)$ explicitly embraces (an informal version of) $\left(2^{*}\right)$, he does not attempt to justify it. And it is actually not clear how one could justify it. To raise a claim and to satisfy it are clearly two different things; and even though it seems reasonable to assume that a person who raises a claim to correctness will want this claim to be satisfied, this does not amount to a convincing argument in support of $\left(2^{*}\right)$. Of course, one could perhaps argue that if there is anarchy or civil war, there is no legal system at all and therefore no claim to correctness; and in such a case, $\left(2^{*}\right)$ would be trivially true.

Fourthly, I have formulated ( $\left.3^{*}\right)$ and $\left(4^{*}\right)$ in terms of "natural" necessity, but they seem to be better conceived as factual claims, perhaps probability claims. For example, although the claim that if law has no real dimension, then there will be anarchy or civil war seems plausible, it can hardly be said to express any sort of necessary truth.

Fifthly, $\left(3^{*}\right)$ asserts that if there is anarchy or civil war, the claim to correctness cannot be satisfied. But why would this have to be so? Could not a court decision, or a piece of legislation, say, be correct even if it could not be enforced? I would say that it could indeed be correct, and that the question of enforcement is really irrelevant to the question of correctness.

I conclude that Alexy's argument in support of the claim that, necessarily, law has a real dimension, is invalid, and that even if it were valid, it would not be sound. ${ }^{10} \mathrm{As}$ I see it, the main problem as regards the validity of the argument is that the premises are too weak to be able to entail a conclusion formulated in terms of conceptual necessity, which is what Alexy needs. The three objections concerning the soundness of the argument seem to me to be of roughly equal strength, and together they indicate that premises $\left(2^{*}\right)-\left(4^{*}\right)$ are false.

Let us note, however, that Alexy is well aware not only that he is invoking the notion of normative necessity in his argumentation (see the quotation above), but also (as we saw in Section 3) that normative and conceptual necessity are very different, and that normative necessity is necessity only in a broader sense of "necessity." In addition, as we saw in Section 2, he points out that the participants in the contemporary debate

\footnotetext{
9 While ( $\square \mathrm{p} \rightarrow \mathrm{p}$ ) is an axiom in almost all systems of modal logic, $(\mathrm{p} \rightarrow \square \mathrm{p})$ is not an axiom in any such system. See, e.g., Garson 2007, 114-33.

10 A valid argument is one in which the conclusion follows from the premises, and a sound argument is a valid argument in which the premises are true. On this, see, e.g., Sainsbury 2001, $30-2$.
} 
about the nature of law agree, on the whole, that in addition to analytical arguments, they must take into account normative arguments, and that there are normatively necessary connections between law and morality. This awareness cannot, however, change the fact that he also holds that an inquiry into the nature of law needs to take the form of an analysis of the concept of law, and this must reasonably mean that he is concerned with conceptual necessity-if he is not, he should say so. For, as we have seen (in Section 2), he maintains (in the quotation) that concepts claim to be "adequate to the object" and that in this way they are "intrinsically related to the correctness or truth of the propositions constructed by means of them." At the very least this must mean that his analysis of the concept of law aspires to clarify the nature of law as it is (not as it should be), and that whatever properties law has are conceptually necessary. My conclusion, therefore, is that the argument adduced by Alexy in support of law's real dimension does not satisfy his own methodological standards.

\section{Explication or Conceptual Analysis?}

Given that Alexy is not, strictly speaking, analyzing the concept of law, should we perhaps say that he is best understood as explicating said concept, even if he does not say so? As is well known, to explicate a concept is to refine the concept in order to make it more useful for a certain purpose (on this, see Carnap 1950, 1-8; 1956, 7-8). To judge the adequacy of the explicatum (that which is to do the explicating) in relation to the explicandum (that which is to be explicated), one will have to consider (i) the relation of similarity between explicatum and explicandum, as well as (ii) the exactness, (iii) the fruitfulness, and (iv) the simplicity of the explicatum. That is to say, one wants the explicatum to be similar to the explicandum, but more exact, as well as fruitful and simple. If these conditions are satisfied, the explication is adequate. As should be clear, this means that an explication will not be true or false without qualification, but rather more or less adequate in light of a given purpose. And the assessment will to some extent be a matter of judgment.

To be able to explicate a concept, then, one must begin by deciding what the purpose of the explication is. As far as I can see, Alexy does not formulate a purpose that his explication, if it is an explication, is meant to achieve, but the distinction between the perspective of a participant and the perspective of an observer might be taken to suggest that he does have two different purposes in mind, and that he believes that one may explicate the concept of law differently, depending on whether one has the one or the other purpose in mind. He might reason, more specifically, that the purpose of the explication in the case of the perspective of a participant is to arrive at a concept of law that will be adequate for those who are concerned with the rightness or goodness of legal norms and with their correct interpretation and application, and that the purpose of the explication in the case of the perspective of an observer is to arrive at a concept of law that is adequate for those who are concerned with the question of how courts and other law-applying organs do decide, or will decide, cases, or perhaps, with the question of how citizens do behave in response to the law.

Let us consider the possibility that Alexy is explicating the concept of law within the perspective of a participant. Given this assumption, can he reason as he does and mix conceptual, moral, and other types of argument in his explication, without in effect giving up the enterprise of explicating the concept of law and settling instead for defending 
his choice of a concept of law on moral grounds, as so-called normative positivists do? ${ }^{11}$ I do not think so. As we have seen, the adequacy of an explication of any concept will depend on how well the explicatum meets the above-mentioned four requirements: (i) similarity to the explicandum together with (ii) exactness, (iii) fruitfulness, and (iv) simplicity. And since these requirements concern epistemic, not moral, values, the moral value of the explicatum (or of the acceptance of the explicatum) does not enter the picture.

But what if the purpose of the explication were moral? If the purpose were moral, perhaps the criteria of adequacy would automatically receive a moral content, so that moral arguments could be allowed to play a role in the explication. I do not think this would be the way forward, however. First, even if Alexy were explicating a concept that is clearly a moral concept, say, the concept of a moral right, it simply would not follow that the purpose for which he was explicating it-perhaps to arrive at a concept that is helpful in moral thinking and reasoning-is a moral purpose. Secondly, if the purpose were moral, he would have changed the subject and would have left the domain of science, or scholarship, and entered the domain of morality. Thirdly, I do not believe the purpose of either the participant explication or the observer explication of the concept of law would be well described as a moral purpose. In the former case, as we have seen, the purpose of the explication would be to arrive at a concept of law that is adequate for those who are concerned with the rightness or goodness of legal norms and with their correct interpretation and application; in the latter case, the purpose would be to arrive at a concept of law that is adequate for those who are concerned with questions about how courts and other law-applying organs do decide or will decide cases or, perhaps with questions about how citizens do behave in response to the law. Neither of these purposes is well described as a moral purpose.

I conclude that even if-contrary to appearances-Alexy had intended his analysis to be an explication of the concept of law, he would not have been entitled to make use of moral arguments in his explication. To explicate concepts, including legal and moral concepts, is simply not a moral enterprise. Thus, although normative positivists do invoke moral arguments in support of their analysis of the concept of law along legal positivist lines, they do not think of themselves as being in the business of explicating the concept of law. Hence if Alexy wanted to join the debate with the normative positivists, he would also have to leave the enterprise of analyzing, or explicating, the concept of law behind.

Department of Law

Stockholm University

SE-106 91

Stockholm

Sweden

Email: torben.spaak@juridicum.su.se

11 Jeremy Waldron (2001), for example, argues that we have good moral reasons to accept so-called exclusive legal positivism, which has it that, necessarily, one determines the existence and content of law using exclusively factual criteria, and that (therefore) the separability (or separation) thesis, according to which there is no necessary connection between law and morality, follows. He writes: "The claim of the normative positivists is that the values associated with law, legality, and the rule of law-in a fairly rich sense - can best be achieved if the ordinary operation of such a system does not require people to exercise moral judgment in order to find out what the law is. The testing of this claim - even on the basis that 'ought' implies 'can' - does not really presuppose any purely descriptive, conceptual, or non-normative phase at all. The argument is going to have to be normative all the way down, even beginning with the way we specify the field of contestation" (ibid., 421). 


\section{References}

Alexy, R. 1989. A Theory of Legal Argumentation: The Theory of Rational Discourse as Theory of Legal Justification. Oxford: Oxford University Press.

Alexy, R. 1998. Law and Correctness. In "Legal Theory at the End of the Millennium." Ed. M. D. A. Freeman. Current Legal Problems, 51, 205-21. Oxford: Oxford University Press.

Alexy, R. 1999. A Defence of Radbruch's Formula. In Recrafting the Rule of Law: The Limits of the Legal Order. Ed. D. Dyzenhaus, 15-39. Oxford: Hart Publishing.

Alexy, R. 2002. The Argument from Injustice: A Reply to Legal Positivism. Trans. B. Litschewski Paulson and S. L. Paulson. Oxford: Oxford University Press.

Alexy, R. 2008a. An Answer to Joseph Raz. In Law, Rights and Discourse: The Legal Philosophy of Robert Alexy. Ed. G. Pavlakos, 37-55. Oxford and Portland, OR: Hart Publishing.

Alexy, R. 2008b. On the Concept and Nature of Law. Ratio Juris 21(3): 281-99.

Alexy, R. 2010. The Dual Nature of Law. Ratio Juris 23(2): 167-82.

Alexy, R. 2017. The Ideal Dimension of Law. In The Cambridge Companion to Natural Law Jurisprudence. Ed. G. Duke and R. P. George, 314-41. Cambridge: Cambridge University Press.

Alexy, R. 2018. The Special Case Thesis and the Dual Nature of Law. Ratio Juris 31(3): 254-9.

Åqvist, L. 1967. Good Samaritans, Contrary-to-Duty Imperatives, and Epistemic Obligations. Noûs 1(4): 361-79.

Carnap, R. 1950. Logical Foundations of Probability. Chicago: University of Chicago Press.

Carnap, R. 1956. Meaning and Necessity: A Study in Semantics and Modal Logic. 2nd ed. Chicago: University of Chicago Press.

Coleman, J. 2001. The Practice of Principle. Oxford: Oxford University Press.

Dworkin, R. 1986. Law's Empire. Cambridge, MA: Belknap Press.

Foley, R. 1999. Pragmatic Contradiction. In The Cambridge Dictionary of Philosophy. 2nd ed. Ed. R. Audi, 730. Cambridge: Cambridge University Press.

Garson, J. W. 2007. Modal Logic for Philosophers. 2nd ed. Cambridge: Cambridge University Press.

Harman, G. H. 1965. The Inference to the Best Explanation. Philosophical Review 74(1): 88-95.

Hart, H. L. A. 1958. Positivism and the Separation of Law and Morals. Harvard Law Review 71(4): 593-629.

Hart, H. L. A. 1961. The Concept of Law. Oxford: Clarendon Press.

Hart, H. L. A. 1982. Essays on Bentham: Studies in Jurisprudence and Political Theory. Oxford: Clarendon Press.

Kelsen, H. 1960. Reine Rechtslehre. 2nd ed. Vienna: Österreichische Staatsdruckerei.

Kelsen, H. 1992. Introduction to the Problems of Legal Theory. Trans. B. Litschewski Paulson and S. L. Paulson. Oxford: Oxford University Press. (Orig. pub. in German under the title Reine Rechtslehre [Vienna: Österreichische Staatsdruckerei, 1934].)

Kramer, M. H. 1999. In Defense of Legal Positivism. Oxford: Oxford University Press.

Moore, M. S. 2000. Educating Oneself in Public. Oxford: Oxford University Press.

Pettersson, K. 2010. The Logical Structure of the Moral Concepts: An Essay in Propositional Deontic Logic. Uppsala: Upsala University Department of Philosophy. 
Radbruch, G. 2006. Statutory Lawlessness and Supra-Statutory Law. Trans. B. Litschewski Paulson and S. L. Paulson. Oxford Journal of Legal Studies 26(1): 1-11. (Orig. pub. in German under the title "Gesetzliches Unrecht und Übergesetzliches Recht," Süddeutsche Juristenzeitung 1 [1946]: 105-8.)

Raz, J. 2008. The Argument from Injustice, or How Not to Reply to Legal Positivism. In Law, Rights and Discourse: The Legal Philosophy of Robert Alexy. Ed. G. Pavlakos, 17-35. Oxford and Portland, OR: Hart Publishing.

Raz, J. 2009. Can There Be a Theory of Law? In Between Authority and Interpretation: On the Theory of Law and Practical Reason, 17-46. Oxford: Oxford University Press. Rönnedal, D. 2012. Extensions of Deontic Logic: An Investigation into Some Multi-Modal Systems. Stockholm: Stockholm University.

Sainsbury, M. 2001. Logical Forms: An Introduction to Philosophical Logic. 2nd ed. Oxford: Blackwell.

Spaak, T. 2003. Legal Positivism, Law's Normativity, and the Normative Force of Legal Justification. Ratio Juris 16(4): 469-85.

Spaak, T. 2007. Guidance and Constraint: The Action-Guiding Capacity of Theories of Legal Reasoning. Uppsala: Iustus.

Waldron, J. 2001. Normative (or Ethical) Positivism. In Hart's Postscript: Essays on the Postscript to "The Concept of Law." Ed. J. L. Coleman, 411-33. Oxford: Oxford University Press. 